\title{
Status of low birth weight at a tertiary level hospital in Bangladesh for a selected period of time
}

\author{
Sharmeen Yasmeen ${ }^{\prime}$, Ehsanul Azim² \\ ${ }^{1}$ Professor, ${ }^{2}$ Lecturer, Department of Community Medicine, Bangladesh Medical College, Dhaka, Bangladesh.
}

\begin{abstract}
In Bangladesh, the prevalence of low birth weight (LBW) is unacceptably high. A cross sectional descriptive study was carried out during the period of June to September 2009 among the mothers whose babies were born in Bangladesh Medical College, a tertiary level hospital situated in Dhaka to assess the proportion of LBW babies. A total of 102 mothers were selected purposively whose babies were born within that period. A pre-tested structured questionnaire was used as research instrument and data were collected from them by face to face interviews. Results revealed that the proportion of LBW babies was $25.49 \%(n=26)$. The most of the LBW babies $(30.77 \%)$ were identified whose average monthly family income was less than 5,000 taka. Among 26 LBW babies, $21(80.77 \%)$ and only three $(19.23 \%)$ were born before completing 37 weeks and after completing 37 weeks of the gestational period respectively. Significant association was found between LBW babies and family income $(p<0.001)$, and between LBW babies and pre-term $(p<0.0001)$. It is considered that the present findings of this study will not only help to take future interventions to combat the problem but also serve as a useful basis for future research and planning.
\end{abstract}

Keywords: Low birth weight, Monthly family income, Mother's age and education, Preterm, Gestation period.

\section{Introduction}

Low birth weight (LBW) is one of the major health problems of children both in developed and developing countries. It is one of the most serious challenges in maternal and child health. Its public health significance may be ascribed to numerous factors - high incidence, association with physical and mental retardation, high risk of perinatal and infant mortality and morbidity, human wastage and suffering, the very cost of special care and intensive care units and its association with socio economic under development.

LBW has been defined by the World Health Organization (WHO) as weight at birth of less than 2,500 grams (5.5 pounds) in first hour of delivery. ${ }^{1}$ This practical cut-off for international comparison is based on epidemiological observations that infants weighing less than 2,500 gm are approximately 20 times more likely to die than heavier babies. ${ }^{2}$ A birth weight below 2,500 gm contributes to a range of poor health outcomes which is more common in developing than developed countries. LBW is closely associated with foetal and neonatal mortality and morbidity, inhibited growth and cognitive development of children, and increased risks of chronic diseases later in life. ${ }^{3}$ Many of them suffer from protein-energy malnutrition and infection. ${ }^{3,4}$ Evidence now shows that adults born with LBW

\section{Practice points}

- LBW is closely associated with foetal and neonatal mortality and morbidity, inhibited growth and cognitive development as well as increased risks of chronic diseases later in life.

- This study identified that more than a quarter of the babies born at a tertiary level hospital in Bangladesh had LBW.

- A significant relationship was demonstrated between LBW and other factors e.g. the socio-economic condition of the families, age, education and physical status of the mothers, and the gestational age of the babies etc.

- The findings of the present study will help to implement preventive programs to improve maternal and child health.

- Large-scale studies are needed to identify valid and reliable evidence to outline relevant national policies and guidelines.

face an increased risk of chronic diseases including high blood pressure, non-insulin dependent diabetes mellitus, coronary heart disease and stroke in adulthood. ${ }^{5} \mathrm{LBW}$ is the

Corresponding author: Prof. Sharmeen Yasmeen, Professor, Department of Community Medicine, Bangladesh Medical College, House\# 34, Road\# 14/A, Dhanmondi R/A, Dhaka-1209, Bangladesh. E-mail: sharmeenbmc@yahoo.com. 
single most important factor determining the survival chances of the child. Many of them die during the first year of their life. ${ }^{4,5}$ Every year approximately 17 million infants in developing countries are born with $\mathrm{LBW}^{4}$ and those who survive have little chance of fully reaching their growth potential. The latest regional estimates of LBW range from $25 \%$ in South Asia, where more than one-half of the world's LBW infants are born, to $10 \%$ and $12 \%$ in Sub-Saharan Africa and Latin America, respectively. ${ }^{6}$ Although these rates are higher than the goal of $10 \%$ that was established by the world leaders at the 1990 World Summit for Children, the data for examining trends in developing countries are limited and the quality of data are questionable when available. More than two-thirds of births are not reported in many parts of Africa, Asia, and Latin America, as many deliveries occur in homes or small health clinics. ${ }^{6,7}$ This may result in an underestimation of the proportion of babies with LBW, because lower-income, higher-risk groups may be the least likely to be included in hospital or urban-based data sets.

Being born underweight is one of the major problems faced by infants in Bangladesh. Bangladesh is among the poorest countries of the world, with low socio-cultural, economic and health statistics. As there is no civil registry, it is impossible to obtain reliable information on health statistics. ${ }^{7}$ Also not many studies have been done on newborn babies in Bangladesh. According to WHO health statistics the prevalence of LBW (weight $<2500$ grams) in Bangladesh was about $40 \%$ in $2005 .{ }^{6,7}$

LBW also indicates malnutrition and ill health of the mother. There is a significant and strong correlation between maternal nutrition and the length of pregnancy and birth weight. High incidence of LBW indicates the deficient health status of the mother, inadequate antenatal care and the need for improved care of the newborn babies. ${ }^{6,7}$ It has long been used as an important public health indicator. ${ }^{4}$ LBW is not a proxy for any one dimension of either maternal or perinatal health outcomes. Globally, the indicator is a good summary measure of multifaceted public health problems that include long-term maternal malnutrition, ill health, hard work and poor pregnancy health care. The smaller the baby, the more important it is to monitor his or her growth in the weeks after birth. ${ }^{5,6}$ This is particularly important for infants at high risk of poor feeding and inadequate growth. Countries should therefore be encouraged to ensure accurate and reliable weighing of infants as close to birth as possible.

LBW was regarded as one of the major targets of the Health for All (HFA) initiative and the Millennium Development Goals (MDGs). The goal of reducing the incidence of LBW by at least one third between 2000 and 2010 is one of the major goals of the Declaration, 'A World Fit for Children', and the Plan of Action adopted at the United Nations General Assembly Special Session on Children in 2002. ${ }^{8,9}$ Like other developing countries, quality and quantity of the relevant data for analyzing trends of LBW in Bangladesh is lacking. ${ }^{10}$ The current study is aimed at identifying the proportion of LBW at a tertiary level hospital in Bangladesh for a selected period of time.

\section{Methods and Materials}

This was a cross-sectional type of descriptive study. The respondents were all mothers who delivered babies consisting of low and normal birth weight in Bangladesh Medical College Hospital (a tertiary level hospital in the capital city of Dhaka), over a period of three months between June to September 2009. Official permission for the study was obtained from the Director and Department of Gynecology and Obstetrics of the hospital. A purposive sampling technique was used to select 102 newborn babies and their mothers. A structured questionnaire was prepared in light of the objectives. It was then pre-tested and a final questionnaire was prepared to interview the admitted mothers in the Gynecology and Obstetric ward of the hospital. The purpose of the study was clearly explained to the respondents prior to taking informed consent from them. The data was collected throughout the study period by face to face interviews with the respondents and the questionnaire was filled in by the interviewers. The data were analyzed by using the Statistical Package for the Social Sciences, version 16.0 (SPSS, Inc, Chicago, IL). A bivariable analysis with Chi-square test $\left(\chi^{2}\right)$ was done as test of significance.

\section{Results}

Among the respondents, the major age group was 20-25 years $(46 \%)$ and about $52 \%$ of the respondents were educated at undergraduate level (Table 1). About two-fifths of the respondents $(38 \%)$ had average monthly family income of Tk.10,000-15,000 and 13\% had monthly family income of $<$ Tk.5,000 (Table 2). The maximum percentage of LBW babies $(30.77 \%)$ were born in families with an income of $<$ Tk.5,000, while the minimum percentage of

Table 1: Socio-demographic characteristics of the

\begin{tabular}{|c|c|}
\hline Characteristics & Respondents (\%) \\
\hline \multicolumn{2}{|l|}{ Age group } \\
\hline $20-25$ & $47(46 \%)$ \\
\hline $26-30$ & $36(35 \%)$ \\
\hline $31-35$ & $15(15 \%)$ \\
\hline $36-40$ & $4(4 \%)$ \\
\hline \multicolumn{2}{|c|}{ Level of education } \\
\hline $\mathrm{SSC}$ & $2(2 \%)$ \\
\hline HSC & $11(11 \%)$ \\
\hline Under graduate & $52(52 \%)$ \\
\hline Graduate & $31(31 \%)$ \\
\hline Post graduate & $4(4 \%)$ \\
\hline
\end{tabular}


Table 2: Distribution of monthly family income of the respondents

\begin{tabular}{|c|c|c|c|}
\hline $\begin{array}{c}\text { Income } \\
(\mathrm{Tk})\end{array}$ & $\begin{array}{c}\text { LBW babies } \\
(1.5-2.49 \mathrm{~kg})\end{array}$ & $\begin{array}{c}\text { Normal birth weight babies } \\
(2.5-3.99 \mathrm{~kg})\end{array}$ & $\begin{array}{c}\text { Total no. of respondents } \\
(\%)\end{array}$ \\
& Respondents $(\%)$ & Respondents $(\%)$ & $13(13 \%)$ \\
\hline 5,000 & $8(31 \%)$ & $5(7 \%)$ & $20(20 \%)$ \\
\hline $10,000-15,000$ & $7(27 \%)$ & $13(17 \%)$ & $39(38 \%)$ \\
\hline$>15,000$ & $7(27 \%)$ & $32(42 \%)$ & $30(29 \%)$ \\
\hline
\end{tabular}

LBW babies (16.67\%) were born in the $<$ Tk.15,000 family income group. A significant association was observed among family income and $\operatorname{LBW}\left(\chi^{2}=21.37, \mathrm{p}<0.001\right)$. All the respondents received a balanced diet and extra nutrients. However, only $97 \%$ of the respondents received iron and folic acid supplements.

Out of 102 babies, 37 (36\%) were born before completing 37 weeks of the gestation period, whereas 65 (64\%) were born after completing 37 weeks (up to 42 weeks) of the gestation period (Table 3). An almost similar pattern was observed among 76 normal birth weight babies; 16 babies $(21 \%)$ were born before completing 37 weeks of the gestation period and $60(79 \%)$ were born after completing 37 weeks of the gestation period. On the contrary, among 26 LBW babies, 21 (81\%) were born before completing 37 weeks of the gestation period while only 3 (19\%) were born after completing 37 weeks of the gestation period. Association between LBW and gestational age $\left(\chi^{2}=29.89\right)$ was statistically significant at $\mathrm{p}<0.0001$ (not shown). Around one-fourth of the babies (26\%) had LWB while around three-quarters $(75 \%)$ had normal weight.

\section{Discussion}

LBW is considered to be an indicator not only of the health and nutritional status of the pregnant woman but also of the social development of the population of a country. The global prevalence of LBW is $15.5 \%$, which means that about 20.6 million such infants are born each year, with $96.5 \%$ of them in developing countries. There is a significant variation in LBW incidence rates across the United Nations regions, with the highest incidence in SouthCentral Asia (27.1\%) and the lowest in Europe (6.4\%).,

The results of this study showed that the proportion of LBW in a tertiary level hospital is $25.49 \%$, which is low in comparison to other studies. ${ }^{11,12}$ A previous study, conducted on 1,000 pregnant woman in Dhaka Medical College Hospital, reported the rate of LBW was $31.2 \%{ }^{11}$ Another study in Sir Salimullah Medical college, Dhaka found that the incidence of LBW was $45.54 \%$ amongst admitted patients. ${ }^{12}$ Compared to another study done in the Dhaka Shishu Hospital, the current study found that the incidence of LBW was $46.08 \%$ among the young mothers (20-25 years), which is supported by another study conducted at the same hospital which showed an incidence rate of $34.31 \%$ among mothers below 20 years of age. ${ }^{13}$

In the current study, significant association was found among family income $(\mathrm{p}<0.001)$ and LBW. In general, the rate of LBW was higher in low family income groups. Similar findings were observed in other studies in Bangladesh $^{14,15}$ and other countries. ${ }^{11,12}$ This study also reveals that women with low body weight (less than $50 \mathrm{~kg}$ ) were more likely to deliver small babies. Low maternal weight may also increase the risk of prematurity. ${ }^{16}$

In this study, respondents universally received a balanced diet and extra nutrients but iron and folic acid supplementation was not universal. Several studies ${ }^{11,14,16}$ identified an association between maternal nutrition and LBW babies but in this study no significant association was found. As most of the mothers were from better socioeconomic backgrounds, it can be assumed that data may not reflect the actual situation as there is no standard concept of having a balanced diet or extra nutrient supplementation among the respondents.

In several studies worldwide, mothers' smoking during pregnancy was identified as one of the most important risk factors for LBW. ${ }^{2,17-19}$ Only a few respondents were smokers so the prevalence of smoking (cigarettes) may be

Table 3: Distribution of new born babies according to gestation age and birth weight category

\begin{tabular}{|c|c|c|c|}
\hline $\begin{array}{c}\text { Gestational age } \\
(\text { weeks })\end{array}$ & $\begin{array}{c}\text { LBW babies } \\
(1.5-2.49 \mathrm{~kg})\end{array}$ & $\begin{array}{c}\text { Normal birth weight babies } \\
(2.5-3.99 \mathrm{~kg})\end{array}$ & $\begin{array}{c}\text { Total no. of respondents } \\
(\%)\end{array}$ \\
\hline & Respondents $(\%)$ & Respondents $(\%)$ & $37(36 \%)$ \\
\hline $37-42$ weeks & $21(81 \%)$ & $16(21 \%)$ & $65(64 \%)$ \\
\hline
\end{tabular}


underreported in the current study as Bengali women may be reluctant to reveal their smoking habits due to social, cultural, or religious reasons. The current study further identified a significant association between LBW and gestational age $(p<0.0001)$. Other studies ${ }^{20-22}$ confirmed that LBW can result from prematurity.

\section{Limitations}

This cross-sectional study involved only a tertiary hospital based in Dhaka (the capital city) and had a small sample size; therefore, caution needs to be taken to generalize the data to other peripheral hospitals, especially hospitals in primary and secondary care settings.

\section{Conclusion}

This study was conducted to identify the proportion of LBW in a tertiary hospital in Bangladesh. This study identified that more than a quarter of the babies had LBW, and a significant relationship was demonstrated between LBW and other factors e.g. the socio-economic condition of the families, age, education and physical status of the mothers, and the gestational age of the babies. The findings of the present study will help as guidelines to initiate preventive programs to improve maternal and child health. Large-scale national studies involving other primary and secondary care hospitals should be conducted to identify valid and reliable evidence to outline relevant national policies and guidelines.

\section{References}

1. WHO. International statistical classification of diseases and related health problems. $10^{\text {th }}$ Revision. Geneva: World Health Organization, 1992.

2. Kramer MS. Determinants of low birth weight: methodological assessment and meta-analysis. Bull World Health Organ 1987;65:663-737.

3. Barker DJP. Fetal and infant origins of adult disease. London: British Medical Publishing Group, 1992.

4. United Nations Administrative Committee on Coordination/Sub-Committee on Nutrition (ACC/SCN). Fourth Report on the World Nutrition Situation. Geneva: ACC/SCN in collaboration with International Food Policy Research Institute (IFPRI), 2000.

5. Barker DJP. Mothers, babies and health in later life. 2nd ed. Edinburgh: Churchill Livingstone, 1998.

6. UNICEF. The State of the World's Children 1998: a UNICEF report. Malnutrition: causes, consequences, and solutions. Nutr Rev 1998; 56:115-23.

7. WHO. WHO Health Statistics of Bangladesh, 2007. http://www.searo.who.int/EN/Section313/Section151 5_6122.htm (accessed 30 June, 2011).

8. UNICEF \& WHO. Low birth weight: country, regional and global estimates. New York: United Nations Children's Fund, 2004.

9. Lawn JE, Cousens S, Zupan J. Four million neonatal deaths: When? Where? Why? Lancet 2005; 365:891900 .

10. Kawser CA, Islam MN, Selina K. Maternal and socioeconomic risk factors associated with low birth weight. Bangladesh J Child Health 1995; 19:112-13.

11. Wannous S, Arous S. Incidence and determinants of low birth weight in Syrian government hospitals. East Mediterr Health J2001;7:966-74.

12. Roudbari M, Yaghmaei M, Soheili M. Prevalence and risk factors of low-birth-weight infants in Zahedan, Islamic Republic of Iran. East Mediterr Health $J$ 2007;13:838-45.

13. Rahman H. Pregnancy outcome and perinatal mortality in a primary health care project. Dhaka Shishu Hosp J 1987;3:1-9.

14. Begum MR. Bhuiyan AB, Khanam ST. Incidence of low birth weight babies in DMCH. Bangladesh $J$ Obstet 1995;10:26-37.

15. Ali Manjir M, Kawser CA. Very low birth weight infants clinical course in the hospital. Bangladesh $J$ Child Health 1989;13:90-5.

16. WHO. Coverage of Maternity Care: A Listing of Available Information, Geneva: World Health Organization, 2004.

17. Khan MR, Rahman ME. Febrile convulsion. Low birth weight neonates. Essence of pediatrics. 3rd edition. Dhaka, 2003.

18. Rosenberg DC, Buescher PA. The association of maternal smoking with infant mortality and low birth weight in North Carolina, 1999. SCHS Studies No. 135. Raleigh, NC: North Carolina State Center for Health Statistics, 2002.

19. UNICEF. Childinfo.http://www.childinfo.org/eddb/ birthreg/index.htm (accessed June, 2011).

20. Rahman MS, Khatoon SA, Harun Jim. Incidence and problems of low birth weight babies in a special care nursery unit of a teaching hospital. Bangladesh J Coll Phys Surg 1996;14:10-3.

21. Akhter FS. A study on factors related to low birth weight and determinants of early neonatal death in a selected teaching hospital. [dissertation]. Dhaka, Bangladesh: NIPSOM; 1999.

22. Maruoka K, Yagi M, Akazawa K, Kinukawa N, Ueda $\mathrm{K}$, Nose Y. Risk factors for low birth weight in Japanese infants. Acta paediatrica 1998;87:304-9. 